\title{
Late Liver Function With Graft Obtained From Donors Above 65 Years
}

F.M. Regueira, A. Diez-Caballero, I. Herrero, F. Rotellar, J.L. Hernández Lizoáin, J. Quiroga, F. Pardo, and J.A. Cienfuegos

ALTHOUGH liver size diminishes with increasing age, neither the hepatic function nor the hepatic flow are significantly modified by this condition. The consideration of these facts, together with the aging of population and the reduced number of liver donors available, have resulted in the use of elder donors. ${ }^{1-4}$ Although the early function of grafts from donors above 65 years of age has been proven to be as good as that obtained with grafts from young donors, ${ }^{1,5}$ their late function is less known.

\section{MATERIALS AND METHODS}

The late hepatic function of grafts obtained from donors above 65 years old was studied. We reviewed two liver transplant patient groups receiving liver transplantation between January 1997 and June 2000: (1) group A ( $\mathrm{n}=17)$, donors above 65 years of age; and (2) group B ( $=66)$, donors below 65 years. Donor acceptance criteria, surgical preservation and transplantation technique, recipient selection criteria, and postsurgery care were similar for both groups.

The early hepatic function was studied through the following parameters: maximum AST and ALT values, prothrombin time activity (\%) (PT), seventh-day bilirubin, length of hospital stay, graft primary nonfunction, and development of initial poor function (defined as elevation of ALT or AST above $2000 \mathrm{U}$ and PT activity below 40\%). The late hepatic function was characterized by hepatic function at 1-year post transplantation, late surgical complications, and recurrence of hepatic disease. Graft and patient survival curves were calculated using Kaplan-Meier estimates, and the different curves were compared using log-rank statistics.

\section{RESULTS}

Average donor age was $70 \pm 3.8$ years for group A, and $39 \pm 17.2$ years for group $\mathrm{B}(P<.001)$. No differences were observed between both groups regarding cause of death, length of stay in the intensive care unit, hypotension, and hypernatremia. Average recipient age was $61.6 \pm 7.2$ years for group A and $57.1 \pm 9.1$ years for group B $(P=.30)$. No differences were observed between both groups regarding waiting time on the transplant list or the cause and severity of hepatic disease according to Child-Pugh classification. Eight recipients in group A (47\%) and 24 in group B (36.4\%) $(P=.419)$ had hepatocarcinoma. The time of cold ischemia was $5.11 \pm 1.2$ hours for group $\mathrm{A}$ and $5.16 \pm 1.39$ hours for group $\mathrm{B}(P=.546)$. The times of warm ischemia were $0.65 \pm$ 0.17 hours and $0.62 \pm 0.15$ hours for groups $A$ and $B$, respectively $(P=.887)$. No differences were observed regarding transfusion of packed red blood cells and plasma.

From the Department of Surgery and Liver Unit, University Clinic of Navarra, Pamplona, Spain.

Address reprint requests to F.M. Regueira, Department of General Surgery, Clinica University, Avda Pio XII, No. 36, 31008 Pamplona, Spain. 
The data of early and late post-transplant parameters are given in Table 1 . There were no differences in maximum AST and ALT values or minimum PT and bilirubin values. No primary nonfunction was observed in any case; and no significant differences in the development of poor initial function were observed between both groups: two patients (11.7\%) in group A and five patients $(7.5 \%)$ in group B $(P=.94)$.

Six patients in group A (35.3\%) presented late surgical complications: two with hepatic artery thrombosis, three with biliary fistula after removal of $\mathrm{T}$ tube, and one with biliary stenosis. In group B, a total of 17 patients (25.7\%) showed late surgical complications: 11 with biliary fistules after removal of $\mathrm{T}$ tube, two with portal vein thrombosis, two with biliary stenosis, one with inferior vena cava stenosis, and one with arterial stenosis.

After an average patient follow up of 22.9 months, the hepatic function was normal in 11 patients $(68.7 \%)$ from group A and in $44(72.1 \%)$ from group B $(P=.89)$. No differences were observed in bilirubin values at 1-year between groups A $(1.08 \pm 0.4 \mathrm{mg} / \mathrm{dL})$ and $\mathrm{B}(1.42 \pm 1.8$ $\mathrm{mg} / \mathrm{dL}$ ). Four patients in group A and 14 patients in group B show altered hepatic test results due to recurrent viral hepatitis in the graft. In group A, one patient died because of arterial thrombosis, and another patient had to undergo retransplantation for the same cause. In group B, five deaths occurred: two due to infections, two due to recurrent disease, and one because of a renal tumor. Patient survival rates at 2 years were $88.9 \%$ in group A and $93.4 \%$ in group B $(P=.901)$. Graft survival rates at 2 years were $83.6 \%$ and $93.4 \%$ for groups $A$ and $B$, respectively $(P=.797)$.

\section{DISCUSSION}

Twenty percent of the liver grafts transplanted during the period of study were obtained from donors above 65 years of age. The consideration of these subjects as potential donors allowed for an expanded pool of donors with no adverse impact on short- and long-term graft function. In this study, the two patient groups considered were similar regarding donor, recipient, and transplantation characteristics affecting graft function. The excellent early function observed may be due to the short times of ischemia, of known significance in transplanting older livers. ${ }^{2,6}$ We also observed good late function with these grafts, without the appearance of the cholestatic pattern previously reported. ${ }^{2,7}$ Almost $60 \%$ of the patients in group A show normal function, and only $25 \%$ have abnormal hepatic test results due to recurrence of liver disease. These data are similar to what is observed with young grafts. ${ }^{3}$ Patient and graft survival rates were $88 \%$ and $83 \%$ respectively, also very similar to those obtained with young livers. ${ }^{1,2}$ Although the rate of surgical complications was similar in both groups, and none of the sepsis complications previously described were observed, it was noted that the arterial thrombosis only occurred with old liver grafts, and that was caused by technical problems and not by graft arterial damage. ${ }^{8}$

The present clinical study demonstrates good long-term results obtained with liver grafts from elderly donors, with times of ischemia close to 6 hours, and proves the suitability of these donors for any type of recipient, beyond their previous restriction to critical transplant patients.

\section{REFERENCES}

1. Emre S, Schwartz ME, Altaca G, et al: Transplantation 62:62, 1996

2. Washburn W, Johnson L, Lewis D, et al: Transplantation 61:1062, 1996 
3. Marino IR, Doyle HR, Aldrighetti L, et al: Hepatology 22:1754, 1995

4. Jimenez Romero C, Moreno Gonzalez E, Colina Ruiz F, et al: Transplantation 68:572, 1999

5. Alexander JW, Vaughn WK, Carey MA: Transplant Proc 23:905, 1991

6. Adams R, Sanchez I, Astarcioglu I, et al: Transplant Proc 27:1181, 1995

7. Yersiz H, Shaked A, Olthoff K, et al: Transplantation 60:790, 1995

8. Debakey M, Lawric GM, Glaeser DH: Ann Surg 201:115, 198 
Table 1. Comparision of Early and Late post-trasplant Parameters in Donors Older than 65 Years (Group A) and Less than 65 Years (Group B)

\begin{tabular}{|c|c|c|c|}
\hline & $\begin{array}{c}\text { Group A } \\
(n=17)\end{array}$ & $\begin{array}{l}\text { Group B } \\
(n=66)\end{array}$ & $P$ \\
\hline \multicolumn{4}{|l|}{ Early } \\
\hline Peak AST (IU/L) & 578 & 663 & .993 \\
\hline Peak ALT (IU/L) & 445 & 544 & .996 \\
\hline Minimum PT (\%) & 51.1 & 52.4 & .208 \\
\hline Bilirubin $7^{\circ}$ day (mg/dL) & 4.41 & 5.92 & .208 \\
\hline Poor initial function (\%) & 11.7 & 7.5 & .948 \\
\hline Hospital stay (days) & 10.1 & 11.3 & .677 \\
\hline \multicolumn{4}{|l|}{$\underline{\text { Late }}$} \\
\hline 2-year patient survival (\%) & 88.89 & 93.44 & .901 \\
\hline 2-year graft survival (\%) & 83.66 & 93.44 & .797 \\
\hline Surgical complications (\%) & 35.30 & 25.7 & .630 \\
\hline Normal liver test (\%) & 68.75 & 72.13 & .890 \\
\hline Bilirubin 1-year post (mg/dL) & 1.08 & 1.42 & .322 \\
\hline Recurrent viral hepatitis (\%) & 25 & 22.9 & .940 \\
\hline
\end{tabular}

